\title{
PRELIMINARY EXPERIENCE WITH EXTRAPERITONEAL ENDOSCOPIC RADICAL PROSTATECTOMY THROUGH DUPLICATION OF THE OPEN TECHNIQUE
}

\author{
M. TOBIAS-MACHADO, MARCO T. C. LASMAR, JIMMY J. A. MEDINA, PEDRO H. \\ FORSETO JR, ROBERTO V. JULIANO, ERIC R. WROCLAWSKI
}

Section of Urology, ABC Medical School, Santo Andre, Sao Paulo, SP

\begin{abstract}
Objective: To describe surgical and functional results with extraperitoneal laparoscopic radical prostatectomy with duplication of the open technique, from the experience obtained in the treatment of 28 initial cases.

Materials and Methods: In a 36-month period, we prospectively analyzed 28 patients diagnosed with localized prostate cancer undergoing extraperitoneal laparoscopic radical prostatectomy.

Results: Mean surgical time was $280 \mathrm{~min}$, with mean blood loss of $320 \mathrm{~mL}$. As intraoperative complications, there were 2 rectal lesions repaired with laparoscopic suture in 2 planes. There was no conversion to open surgery. Median hospital stay was 3 days, with return to oral diet in the first postoperative day in patients. As post-operative complications, there were 3 cases of extraperitoneal urinary fistula. Two of these cases were resolved by maintaining a Foley catheter for 21 days, and the other one by late endoscopic reintervention for repositioning the catheter. Five out of 18 previously potent patients evolved with erectile dysfunction. The diagnosis of prostate cancer was confirmed in all patients, with focal positive margin occurring in 3 cases. During a mean follow-up of 18 months, 2 patients presented increased PSA, with no clinical evidence of disease.

Conclusion: Laparoscopic radical prostatectomy is a laborious and difficult procedure, with a long learning curve. Extraperitoneal access is feasible, and it is possible to practically duplicate the principles of open surgery. The present technique can possibly offer advantages in terms of decreased blood loss, preservation of erectile function and prevention of positive margins.
\end{abstract}

Key words: prostatic neoplasms; prostatectomy; retroperitoneum; endoscopy

Int Braz J Urol. 2005; 31: 228-35

\section{INTRODUCTION}

Early experiences with laparoscopic radical prostatectomy were developed by transperitoneal approach. The surgery was first reported by Schuessler et al. in 1992, but technical difficulties prevented the diffusion of its practical application (1). In 1998, Guillonneau \& Vallencien (2) introduced the technique of descending laparoscopic radical pros- tatectomy with transperitoneal access, which was reproduced by other services. According to the authors, the initial access to seminal vesicles and ligation without section of the venous complex were essential technical modifications that made the technique's standardization and feasibility of the laparoscopic technique easier.

Raboy et al. (3) described the first report of extraperitoneal laparoscopic radical prostatectomy 
(ELRP). Except for the initial dissection of seminal vesicles, the employed technique followed the principles of the French technique, by sectioning the venous complex and the urethra at the final step of prostatic ablation. Bollens et al. (4) described the first series with a larger number of cases using this technique. In Brazil, laparoscopic radical prostatectomy has been developed in a few centers, being almost exclusively performed by transperitoneal approach.

The present work aims to demonstrate the feasibility of performance, as well as to describe the initial results of the laparoscopic extraperitoneal technique, using the terms classically described by Walsh (5).

\section{MATERIALS AND METHODS}

Between February 2001 and February 2004, we studied 28 patients with clinically localized prostate adenocarcinoma, diagnosed by digital rectal examination, PSA and ultrasound-guided prostate biopsy. Mean age was 66 years (55-73), with mean body mass index of 24 (19-35). Twenty-five (89.3\%) had AS A surgical risk II and 3 patients were ASA I

Table 1 - Demographic data and preoperative characteristics of patients undergoing extraperitoneal endoscopic radical prostatectomy with duplication of open technique.

\begin{tabular}{lc} 
Number of patients & 28 \\
Age (years) & $66(55-73)$ \\
Body mass index & $24(19-35)$ \\
ASA surgical risk (patients) & I (10.7\%); II (89.3\%) \\
Prostate volume - ultrasound (cc) & $51(33-74)$ \\
Prostate Specific Antigen (ng/mL) & $8.0(3-17)$ \\
& \\
Gleason Score & N patients \\
$\geq 7$ & $11(39.3 \%)$ \\
6 & $14(50.0 \%)$ \\
5 & $03(10.7 \%)$ \\
& \\
Clinical stage & \\
T1c & N patients \\
T2a & $11(39.3 \%)$ \\
T2b & $10(35.7 \%)$ \\
\hline
\end{tabular}

$(10.7 \%)$. Two patients had previously undergone transurethral resection of the prostate, 3 had a history of inguinal herniorrhaphy and another 3 had undergone previous surgery with access to the abdominal cavity.

Tumor staging through abdominal and pelvic computerized axial tomography and bone scintigraphy was performed when the serum level of prostate specific antigen (PSA) was higher than $10 \mathrm{ng} /$ $\mathrm{mL}$ or when Gleason score was higher than or equal to 7. Patients with localized disease were selected.

Mean prostate volume as obtained by transrectal ultrasonography was $51 \mathrm{~g}$ (33-74). Mean PSA in this series was $8.0 \mathrm{ng} / \mathrm{mL}(3-17 \mathrm{ng} / \mathrm{mL})$. Clinical stage was T1c in 11 patients $(39.3 \%)$, T2a in 10 patients $(35.7 \%)$ and $\mathrm{T} 2 \mathrm{~b}$ in 7 patients $(25 \%)$.

Among the entire sample, 11 patients (39.3\%) presented Gleason score 7 or higher, 14 patients $(50 \%)$ had Gleason 6, and 3 patients $(10.7 \%)$ had Gleason 5 (Table-1).

Laparoscopic pelvic lymphadenectomy was performed when PSA was higher than $10 \mathrm{ng} / \mathrm{mL}$ and in patients with Gleason score above 7 .

We have described surgical time, blood loss, intraoperative complications, conversion rate, hospital stay, time until returning to oral diet, convalescence period, post-operative complications and histopathological data of the specimen.

Patients were divided into 2 groups in order to assess the learning curve. The first twenty patients formed the first group and the remaining 8 the second group. Patients were followed up on an outpatient basis and assessed at 7,14 and 30 days following discharge from hospital, and then every 3 months during the first 2 years, with clinical examination and PSA measurement. Following this period, follow-up was biannual. Mean follow-up was 18 months.

Mean blood loss was obtained by estimating the amount of blood that was aspired during the procedure.

Potency was assessed through the capacity of maintaining penile rigidity sufficient for sexual intercourse (Item 5 from IIEF). Pre-operatively, 10 patients $(35.7 \%)$ had erectile dysfunction while 18 patients $(64.3 \%)$ had preserved erectile function. In order to assess continence, we considered the criteria 
proposed by Turk et al. (6) and the time to recovery of continence.

All patients were operated at a Brazilian teaching institution by a single surgeon, who was familiar with extraperitoneal access, and was aided by an assistant with expertise in laparoscopy and a training resident doctor for controlling the camera. The protocol was started after previous experience of the surgeon in assisting transperitoneal laparoscopic radical prostatectomy in 30 patients.

The adopted surgical technique was performed through 5 ports, through extraperitoneal space, practically duplicating all steps used in conventional open radical prostatectomy (7). All patients received prophylaxis for venous thrombosis with low molecular weight heparin up to 48 hours following surgery and mobilization in bed after the first 24 hours. Penrose drain was used in all patients, being removed when the output was lower than $100 \mathrm{cc}$ in 24 hours.

\section{RESULTS}

Results are summarized in Table- 2 .

Mean surgical time was 280 minutes (190$420)$. In the first group, mean surgical time was 340 minutes (290-420). Mean time for prostate ablation was 200 minutes (170-220) and mean time for vesicourethral anastomosis was 140 minutes (80-160). In the second group, mean surgical time was 220 minutes (190-260 min) with mean time for prostate ablation being 140 minutes (90-160 $\mathrm{min}$ ) and 80 minutes (45-110) for vesicourethral anastomosis. Laparoscopic obturator lymphadenectomy was performed in 8 patients with mean additional time of 42.5 minutes (35-50).

Mean blood loss was $320 \mathrm{~mL}$ (110-820). The patient that lost $820 \mathrm{~mL}$ of blood was the second in the series and required transfusion during surgery. Mean blood loss for the first and the second groups was respectively 500 and $140 \mathrm{~mL}$.

Among intraoperative complications, there were 2 rectal lesions, which were laparoscopically sutured in 2 planes of 3-0 polyglactin. The complications occurred in the first group. There was no conversion to open surgery in this series.
Analgesia was offered with paracetamol and ketoprofen during the first 24 hours and, following this period, only if the patient complained of pain. Nine $9(35.7 \%)$ patients require re-administration of ketoprofen. Only $3(10.7 \%)$ patients used opioids due to more significant pain.

Mean time until restitution of oral diet was 24 hours (12-36 hours).

Patients had a median hospital stay of 3 days

On the seventh postoperative day, a cystography was performed and the Foley catheter was removed after confirming that there was no extravasation of urine. If any urine escape persisted, a new cystography was performed on the 14th post-operative day. Patients were discharged from hospital with the Foley catheter. Mean period of catheter maintenance was 11 days in the first group and 7 days in the second one.

Of the 2 cases presenting rectal lesion, one required reoperation for loop colostomy on the 4th postoperative day. Extraperitoneal urinary fistulas

Table 2 - Surgical data from patients undergoing extraperitoneal endoscopic radical prostatectomy with duplication of open technique.

\begin{tabular}{lc}
\hline Surgical time (min) & $280(190-420)$ \\
Blood loss (mL) & $320(110-820)$ \\
Intraoperative complications & Rectal damage (2) \\
Conversions & 0 \\
Introduction of oral diet (hours) & $24(12-36)$ \\
Hospital stay (days) & $3(1.5-9)$ \\
Return to activities (weeks) & $4(3-6)$ \\
& \\
Preoperative complications & 3 \\
$\quad$ Urinary fistula & 1 \\
Colostomy & \\
Pathological stage & $\mathrm{N}$ patients \\
$\quad$ T2a & $14(50.0 \%)$ \\
$\quad$ T2b & $10(35.7 \%)$ \\
$\quad$ T3a & $4(14.3 \%)$ \\
Positive surgical margins & \\
Erectile dysfunction & $3(10.7 \%)$ \\
Urinary incontinence & $5(27.7 \%)$ \\
\hline
\end{tabular}


occurred in 3 patients, with 2 cases being resolved by maintaining the Foley catheter for 21 days. The third case presented high-output urinary fistula, where we observed loosening of the vesicourethral anastomosis due to improper positioning of the balloon. This case required endoscopic repositioning of the catheter, with resolution within 4 days from the intervention.

Mean volume of the removed specimen was $44 \mathrm{~g}$ (31-76) and the histological diagnosis of prostate adenocarcinoma was confirmed in all patients. Pathological stage was T2a in 14 patients (50\%), T2b in 10 patients (35.7\%), T3 in 4 patients (14.3\%). Three patients with T3 stage showed focal involvement in the lateral margins. Local or systemic clinical recurrence was not evidence in the study period. Pathological result for patients undergoing lymphadenectomy was negative to neoplasia in all patients. Two patients with pT3 stage had biochemical recurrence with PSA levels of 1.0 and $1.2 \mathrm{ng} / \mathrm{mL} 6$ and 18 months following surgery, and were rescued by external radiotherapy. There was no event leading to the suspicion of clinical recurrence.

\section{Functional Results}

Fourteen patients $(50 \%)$ showed complete urinary continence until the third month. On the sixth month, another 8 (28.6\%) patients were continent. When assessing the remaining patients after 12 months, 4 (14.3\%) of those who used 2 day pads and one night pad gained continence. Thus, after one year, $92.9 \%$ of the patients were completely continent.

Of the $2(7.1 \%)$ incontinent patients, 1 was diagnosed with stenosis of the vesicourethral anastomosis and underwent endoscopic treatment, with good results concerning urethral permeability. One patient is still incontinent using 4 day pads and 2 night pads and currently has a surgery planned in order to place an artificial sphincter.

The preservation of the neurovascular bundle was performed bilaterally when PSA was lower than $10 \mathrm{ng} / \mathrm{mL}$ or when no lateral nodule was palpable on the digital rectal examination. Of the 18 patients with pre-operative potency, 2 presented intraoperative macroscopic features of extracapsular tumor, which prevented preservation of the nervous bundle. The patient was considered as definitely impotent when he was not able to achieve erection, both spontaneously or with the use of oral or intracavernous drugs, within a 1-year period.

Eight patients (44.4\%) recovered potency up to the third month and another $5(27.7 \%)$ recovered their potency within one year. Among the 13 potent patients, 6 required inhibitors of type 5 phosphodiesterase in order to maintain an adequate sexual intercourse.

The remaining five $(27.7 \%)$ patients, where the use of oral medication or intracavernous injections was not effective within 1 year following the surgery, have surgical plans for placing a penile prosthesis (Figure-1).

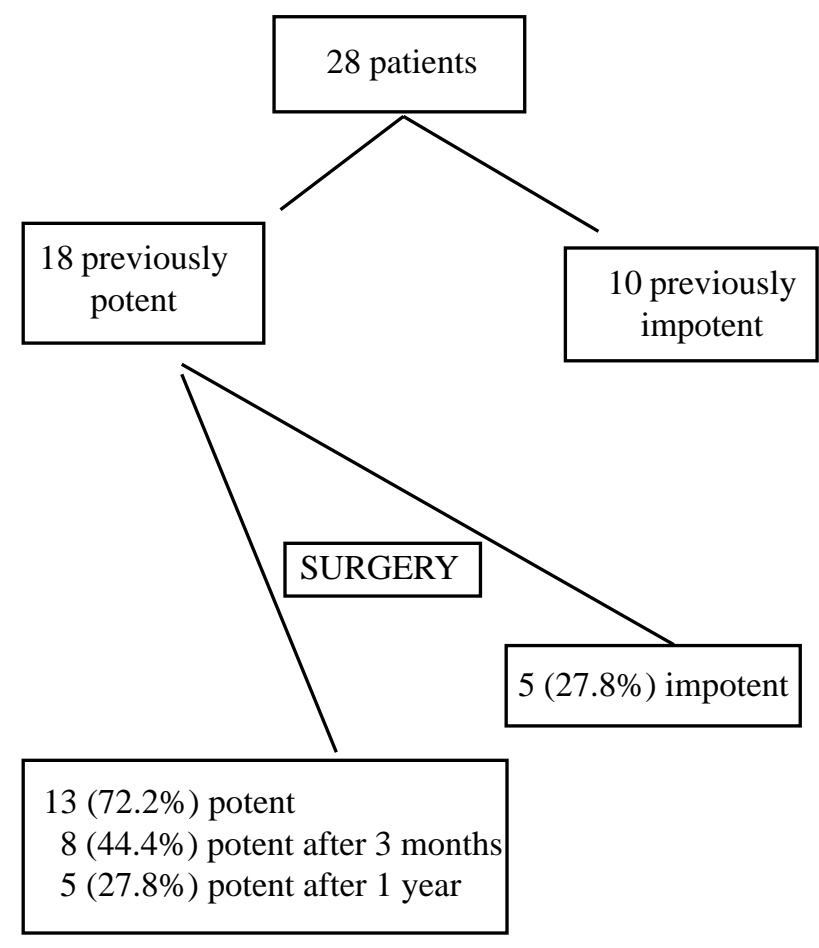

Figure 1 - Sexual function of patients undergoing extraperitoneal endoscopic radical prostatectomy with duplication of open technique. 


\section{COMMENTS}

Recently, laparoscopic radical prostatectomy has been introduced aiming to decrease operative morbidity, while keeping the functional and oncological features of conventional technique (1).

Laparoscopic technique offers advantages, especially concerning the access to deeper organs that are surrounded by bony structures, where the surgical field is too limited for open surgical maneuvers. It allows better viewing due to magnification and selective illumination of the structures, thus increasing the accuracy of dissection and favoring more delicate technical maneuvers. Therefore, the potential for preserving neurovascular and muscular structures is increased (8). Robotic assistance, when available, allows better stabilization of image, reducing surgical time and refining the confection of the vesicourethral anastomosis. (9).

Some authors have demonstrated that laparoscopic radical prostatectomy provides functional and oncological results that are comparable with the open technique, however with significant decrease in blood transfusion rate, shorter hospital stay and faster recovery $(8,10)$. Guillonneau et al. in 2002, in a series of 567 patients, reported that $82.9 \%$ did not present complications, stating that this access has lower morbidity than open retropubic surgery (10). Subsequently, the same authors on the following year, now with 1000 patients, concluded that the laparoscopic radical prostatectomy presents satisfactory results concerning tumor control and biochemical recurrence, in addition to being comparable to the open technique in terms of follow-up and results (11).

In 2002, Salomon et al. showed in their work that, after one year, laparoscopic prostatectomy resulted in urinary continence in $90 \%$ of patients and preservation of potency in $58.8 \%$ and up to $83.8 \%$ in the subgroup of patients under 60 years old (12). Rozet et al. found similar results in 2004, with the extraperitoneal laparoscopic approach (13).

The strictly extraperitoneal laparoscopic radical prostatectomy has gained higher acceptance worldwide. It combines the benefits of the laparoscopic approach (less painful, lower morbidity, faster recovery, better cosmetic effect) with the advantages of the open retropubic surgery. It reduces the risks of damaging intraperitoneal organs, prolonged adynamic ileus, intracavitary tumor spread, as well as bleeding or urine extravasations into the peritoneal cavity. Some authors also believe that it allows better dissection of the neurovascular, as demonstrated in other series $(14,15)$.

One limitation of the extraperitoneal access is the reduced working place for manipulating the forceps, especially when performing aspiration or when there is peritoneal perforation. The majority of difficulties are overcome with training and adaptation to the reduced working place by the surgeon, as well as with the proper withdrawing and exposure of structures by the assistance.

The majority of centers that use extraperitoneal access employ an antegrade technique. According to this technique's adepts, the position of the camera and working forceps in relation to the prostate would promote greater difficulties for performing the surgery by retrograde access. With the approached used in the present study, the proximal retraction of the catheter by the assistant allows the elevation of the prostate apex and proper visualization of the retroprostatic space, as occurs in the open technique.

Though $\mathrm{CO}_{2}$ absorption is slightly higher in the extraperitoneal approach, no clinically significant adverse hemodynamic or respiratory effects have been found, when compared with the transperitoneal approach (16).

The intraoperative and oncological results of transperitoneal and antegrade extraperitoneal laparoscopic radical prostatectomy were compared by Cathelineau et al. (17), who considered them equivalent. Though the surgical time was significantly shorter in extraperitoneal approach, these authors concluded that the selection of access should depend on the surgeon's expertise and training. Erdogru et al. (18) verified this equivalence as well, recommending the extraperitoneal approach in particular for cases of obesity, previous abdominal surgery and requirement of concomitant inguinal hernia repair.

In the present study, the technique of endoscopic radical prostatectomy was totally extraperitoneal and duplicated all the steps of Walsh's technique, differing from other techniques reported in the literature. 
In 2003, Dubernard et al. (19) published an extraperitoneal approach characterized by retrograde dissection of the prostate, releasing the retroprostatic space immediately after the ligation of the dorsal vein complex and urethral sectioning. The technique employed in our work differs from the one described by those authors due to control of "back flow" and ligation of the postero-lateral pedicle of the prostate with polymer clips. The dissection of the neurovascular bundle is performed in retrograde and antegrade directions, similarly to the technique described in 2004 by $\mathrm{Su}$ et al. (20). Additionally, the vesicourethral anastomosis is performed with a continuous suture forming 2 hemicircumference as described by Van Velthoven et al., thus reducing the learning curve and providing greater safety as for the anastomosis' final results (21).

The surgical time obtained in this work was comparable to other world series on preliminary experience $(4,6)$. We have also observed a decrease of 120 minutes in mean total surgical time in the last cases, with the possibility of further reductions as the learning curve is overcome.

Blood loss was lower in this sample than in some other series from the literature $(4,17)$, with low transfusion rate. This fact can result from the familiarity with already known steps from open surgery technique, in addition to using clips in the prostate pedicles (Table-3).
Analgesia and hospital stay were similar to other results reported in the literature $(4,6,15)$.

The most serious complication in this sample was rectal damage, probably related to the initial retroprostatic dissection and the learning curve.

Post-operative complications were urinary fistulas, however they had no major repercussion on the general status and were easily resolved in all patients, advantages that are attributed to the extraperitoneal approach. The occurrence of subcutaneous emphysema is quite frequent, however its clinical repercussion is not significant, if there is proper intraoperative anesthetic management, with good hydration and hyperventilation in order to avoid hypercarbia.

In relation to oncological control, the extraperitoneal approach seems to offer the same early oncological results, with shorter surgical time. Ruiz et al. (22) in a comparative series of trans- and extraperitoneal laparoscopic prostatectomies observed that oncological control and positive margins were similar, though cases operated by extraperitoneal access had been preoperatively classified as more aggressive.

Our initial impression is that it is possible to reduce the index of positive margins in the learning curve when compared with other series of laparoscopic radical prostatectomy. We believe that the technique described in this study offers clearer visualization of the prostate contour, since the pros-

Table 3 - Data from some early series on extraperitoneal endoscopic radical prostatectomy.

\begin{tabular}{|c|c|c|c|c|c|}
\hline & $\begin{array}{l}\text { Bollens et al., } \\
2001 \text { (ref 4) }\end{array}$ & $\begin{array}{l}\text { Stolzenburg et al., } \\
2003 \text { (ref 14) }\end{array}$ & $\begin{array}{l}\text { Cathelineau et al., } \\
2004 \text { (ref 17) }\end{array}$ & $\begin{array}{c}\text { Ruiz et al., } \\
2004 \text { (ref 22) }\end{array}$ & $\begin{array}{c}\text { Present } \\
\text { Series }\end{array}$ \\
\hline $\mathrm{N}$ cases & 50 & 70 & 100 & 165 & 28 \\
\hline PSA (mean) & 9.1 & 12.5 & 10.0 & & 8.0 \\
\hline Surgical time & 317 & 155 & 163 & 220 & 280 \\
\hline Blood loss (mL) & 680 & 350 & 375 & 803 & 320 \\
\hline+ Margins (\%) & 22 & 41.2 & 21 & 29.7 & 10.7 \\
\hline Major complications* & 1 conversion & 0 & 0 & 2 rectal lesions & 2 rectal lesions \\
\hline $\begin{array}{l}\text { Urinary continence } \\
\text { after } 1 \text { year }(\%)\end{array}$ & 85 & 97.1 & - & - & 929 \\
\hline $\begin{array}{l}\text { Sexual potency } \\
\text { after } 1 \text { year }(\%)\end{array}$ & 67 & - & - & - & 72.2 \\
\hline
\end{tabular}

* Major complications: conversions, hypovolemic shock, rectal damage. 
tate is fixed to the pelvic floor only by its lateral pedicles at the end of the procedure. The reduced rate of positive surgical margins seem to be an advantage with this technique, however, the small number of cases and the preoperative selection of patients for this approach do not allow a definitive conclusion.

Functional control, as characterized by continence, showed no major differences when compared with other world series $(4,15)$. However, Eden et al. reported that urinary continence happened earlier with the extraperitoneal approach due to larger dissection and consequent bladder denervation that occurs in the transperitoneal approach (23). In relation to sexual potency, results were quite satisfactory, which can be explained by the clear identification of the pedicle and the use of clip in the prostate pedicles, thus preventing the heat to be transmitted to the neurovascular bundle.

\section{CONCLUSION}

Extraperitoneal laparoscopic radical prostatectomy with duplication of the open technique is feasible, even with a recognized learning curve.

This technique can offer potential advantages concerning the reduction in blood loss, preservation of erectile function and prevention of positive surgical margins during the learning curve.

The overall complication rate is compatible with other early series of laparoscopic radical prostatectomy. Urinary fistulas show benign evolution, without prolonged ileus and spontaneous closure only by maintaining the bladder catheter.

\section{REFERENCES}

1. Schuessler WW, Schulam PG, Clayman RV, Kavoussi LR: Laparoscopic radical prostatectomy: initial shortterm experience. Urology. 1997; 50: 854-7.

2. Guillonneau B, Vallancien G: Laparoscopic radical prostatectomy: the Montsouris technique. J Urol. 2000; 63: 1643-9.

3. Raboy A, Ferzli G, Albert P: Initial experience with extraperitoneal endoscopic radical retropubic prostatectomy. Urology. 1997; 50: 849-53.
4. Bollens R, Vanden Bossche M, Roumeguere T, Damoun A, Ekane S, Hoffmann P, et al.: Extraperitoneal laparoscopic radical prostatectomy. Results after 50 cases. Eur Urol. 2001; 40: 65-9.

5. Walsh PC, Donker PJ: Impotence following radical prostatectomy: Insight into etiology and prevention. J Urol. 1982; 128: 492-7.

6. Turk I, Deger S, Winkelmann B, Schonberger B, Loening SA: Laparoscopic radical prostatectomy. Technical aspects and experience with 125 cases. Eur Urol. 2001; 40: 46-52; discussion 53.

7. Tobias-Machado M, Forseto Jr P, Medina JA, Watanabe M, Juliano RV, Wroclawski ER: Laparoscopic radical prostatectomy by extraperitoneal access with duplication of the open technique. Int Braz J Urol. 2004; 30: 221-6.

8. Turk I, Deger S, Winkelmann B, Brettschneider P, Roigas J, Wille A, et al.: Radical prostatectomy in clinically localized prostate carcinoma. Pro Laparoscopic approach. Urologe A. 2002; 41: 48-54.

9. Gettman MT, Hoznek A, Salomon L, Katz R, Borkowski T, Antiphon P, et al.: Laparoscopic radical prostatectomy: description of the extraperitoneal approach using the da Vinci robotic system. J Urol. 2003; 170: 416-9.

10. Guillenneau B, Rozet F, Cathelineau X, Lay F, Barret E, Doublet JD, et al.: Perioperative complications of laparoscopic radical prostatectomy: the Montsouris 3year experience. J Urol. 2002; 167: 51-6.

11. Guillonneau B, El-Fettouh H, Baumert H, Cathelineau X, Doublet JD, Fromont G, et al.: Laparoscopic radical prostatectomy: oncological evalution after 1.000 cases at Montsouris institute. J Urol. 2003; 169: 1261-6.

12. Salomon L, Anastasiadis AG, Katz R, De La Taille A, Saint F, Vordos D, et al.: Urinary continence and erectile function: a prospective evaluation of functional results after radical laparoscopic prostatectomy. Eur Urol. 2002; 42: 338-43.

13. Rozet F, Arroyo C, Cathelineau X, Barret E, Prapotnich D, Vallancien G: Extraperitoneal standard laparoscopic radical prostatectomy. J Endourol. 2004; 18: 605-09; discussion 610.

14. Stolzenburg JU, Truss MC, Do M, Rabenalt R, Pfeiffer $\mathrm{H}$, Dunzinger M, et al.: Evolution of endoscopic extraperitoneal radical prostatectomy (EERPE) - technical improvements and development of a nerve-sparing, potency-preserving approach. World J Urol. 2003; 21: $147-52$.

15. Stolzenburg JU, Do M, Rabenalt R, Pfeiffer H, Horn L, Truss MC, et al.: Endoscopic extraperitoneal radi- 
cal prostatectomy: initial experience after 70 procedures. J Urol. 2003; 169: 2066-71.

16. Meininger D, Byhahn C, Wolfram M, Mierdl S, Kessler P, Westphal K: Prolonged intraperitoneal versus extraperitoneal insufflation of carbon dioxide in patients undergoing totally endoscopic robot-assisted radical prostatectomy. Surg Endosc. 2004; 18: 829-33.

17. Cathelineau X, Cahill D, Widmer H, Rozet F, Baumert $\mathrm{H}$, Vallancien G: Transperitoneal or extraperitoneal approach for laparoscopic radical prostatectomy: a false debate over a real challenge. J Urol. 2004; 171: 714-6.

18. Erdogru T, Teber D, Frede T, Marrero R, Hammady A, Seemann O, Rassweiler J: Comparison of transperitoneal and extraperitoneal laparoscopic radical prostatectomy using match-pair analysis. Eur Urol. 2004; 46: 312-9.

19. Dubernard P, Benchetrit S, Chaffange P, Hamza T, Van Box Som P: Retrograde extraperitoneal laparoscopic prostatectomy (R.E.I.P). Simplified technique (based on a series of 143 cases. Prog Urol. 2003; 13: 163-74.

20. Su LM, Link RE, Bhayani SB, Sullivan W, Pavlovich CP: Nerve-sparing laparoscopic radical prostatectomy: replicating the open surgical technique. Urology. 2004; 64: 123-7.

21. Van Velthoven RF, Ahlering TE, Peltier A, Skarecky DW, Clayman RV: Technique for laparoscopic running urethrovesical anastomosis: the single knot method. Urology. 2003; 61: 699-702.

22. Ruiz L, Salomon L, Hoznek A, Vordos D, Yiou R, de la Taille A, et al.: Comparison of early oncologic results of laparoscopic radical prostatectomy by extraperitoneal versus transperitoneal approach. Eur Urol. 2004; 46:50-4; discussion 54-6.

23. Eden CG, King D, Kooiman GG, Adams TH, Sullivan ME, Vass JA: Transperitoneal or extraperitoneal laparoscopic radical prostatectomy: does the approach matter? J Urol. 2004; 172: 2218-23.

Received: December 14, 2004 Accepted after revision: April 29, 2005

\section{Correspondence address:}

Dr. Marcos Tobias-Machado

Rua Graúna, 104 / 131

São Paulo, SP, 04514-000, Brazil

E-mail: tobias-machado@uol.com.br 